\title{
ORPHAN BREAKWATERS: COLLAPSE AND TRANSMISSION REDUCTION.
}

\author{
William ALLSOP, PhD student, University of Edinburgh, w.allsop@ed.ac.uk; Director, William Allsop Consulting Ltd \\ Tom Bruce, Professor, School of Engineering, University of Edinburgh; \\ Adrian Pearson, Engineer, Moffatt \& Nichol, New Orleans,
}

\section{BACKGROUND}

In the past, many coastal towns or villages constructed harbours for trade and/or fishing. These were protected by breakwaters, commonly rubble mounds to low-water, surmounted by vertical walls of dressed stone blocks (later concrete) with rubble core. Now, 100-150 years later, many such harbours have little or no income to maintain or repair their breakwaters, but meantime, the areas protected have been adopted for commercial and residential purposes, at increased risk of flooding if the 'orphan' breakwater were to collapse, Hampshire et al. (2013).

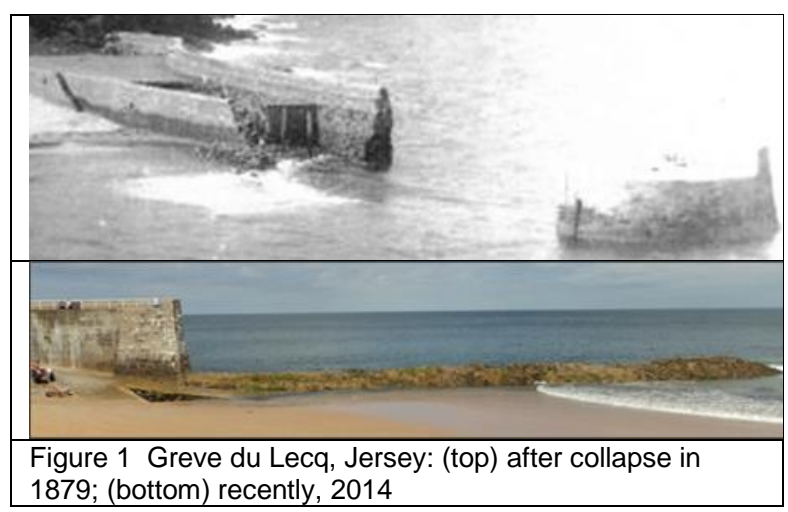

Even after collapse, some wave reduction will however still be afforded by the relict structure, see example in Figure 1.

Tests by Allsop et al (2017) have modelled the collapse of several simplified breakwaters, and measured levels of wave transmission over the collapsed structures. This paper extends that work with more analysis of collapsed crest levels, and hence of likely wave transmission.

\section{HYDRAULIC MODEL STUDIES}

The physical model tests were designed to explore how much (or little!) wave protection might be given by the remains of these types of breakwater after collapse. The main issues are therefore: to what crest level might it be reduced after initial failure; and how large might the transmitted waves be? To do this, the wave tests were designed to reproduce the collapse process as realistically as possible (within project constraints), and then to measure wave transmission.

When the tests were designed, it was not known how many structure variations could be tested. In the event, 6 different structures were tested with 200 individual tests. An example structure is shown in Figure 2.

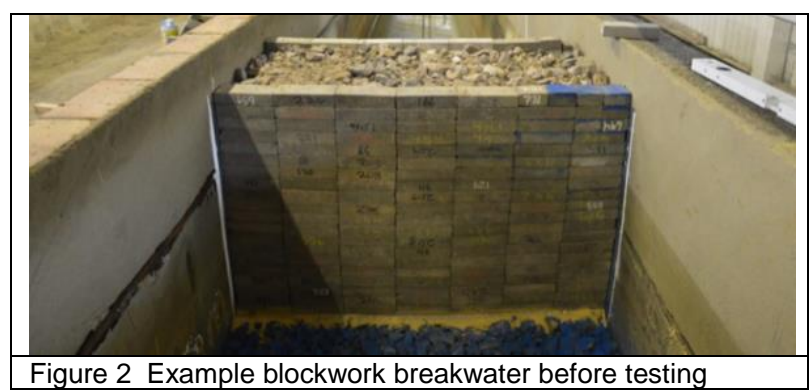

A collapsed breakwater is then shown in Figure 3 . The crest of the collapsed mound is towards the left of the picture. The lower part of the seaward wall is in the centre, a feature found in the remains of the breakwater at Skateraw (Figure 4) abandoned since about 1860.
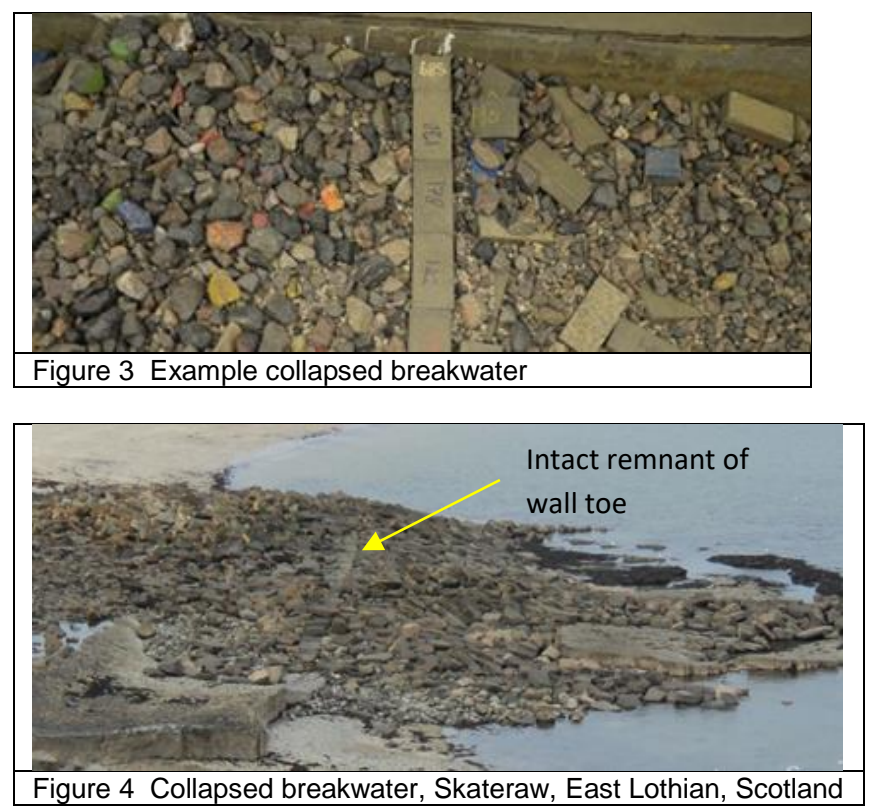

For the model tests, the changes to crest levels from post-test profile measurements (Figure 5) have been analysed relative to various crest recession prediction methods. 


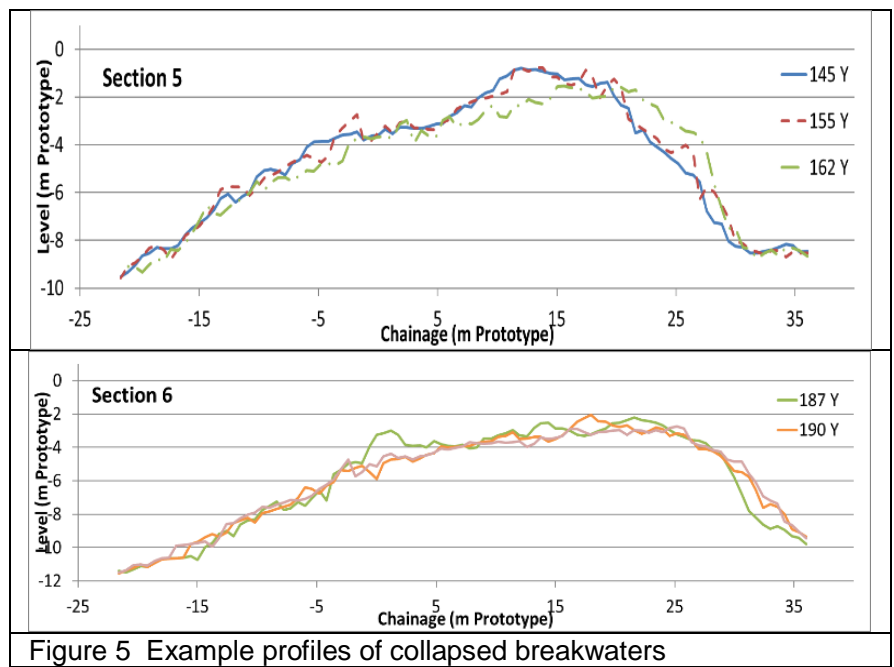

Wave transmission results are shown in Figure 6 as $C_{t}$ vs $R_{c} / H_{s i}$ for each of three wave steepnesses used in these tests, $s=0.06$; $s=0.035 ; s=0.01$ corresponding to 'storm' persistent' and 'swell' conditions

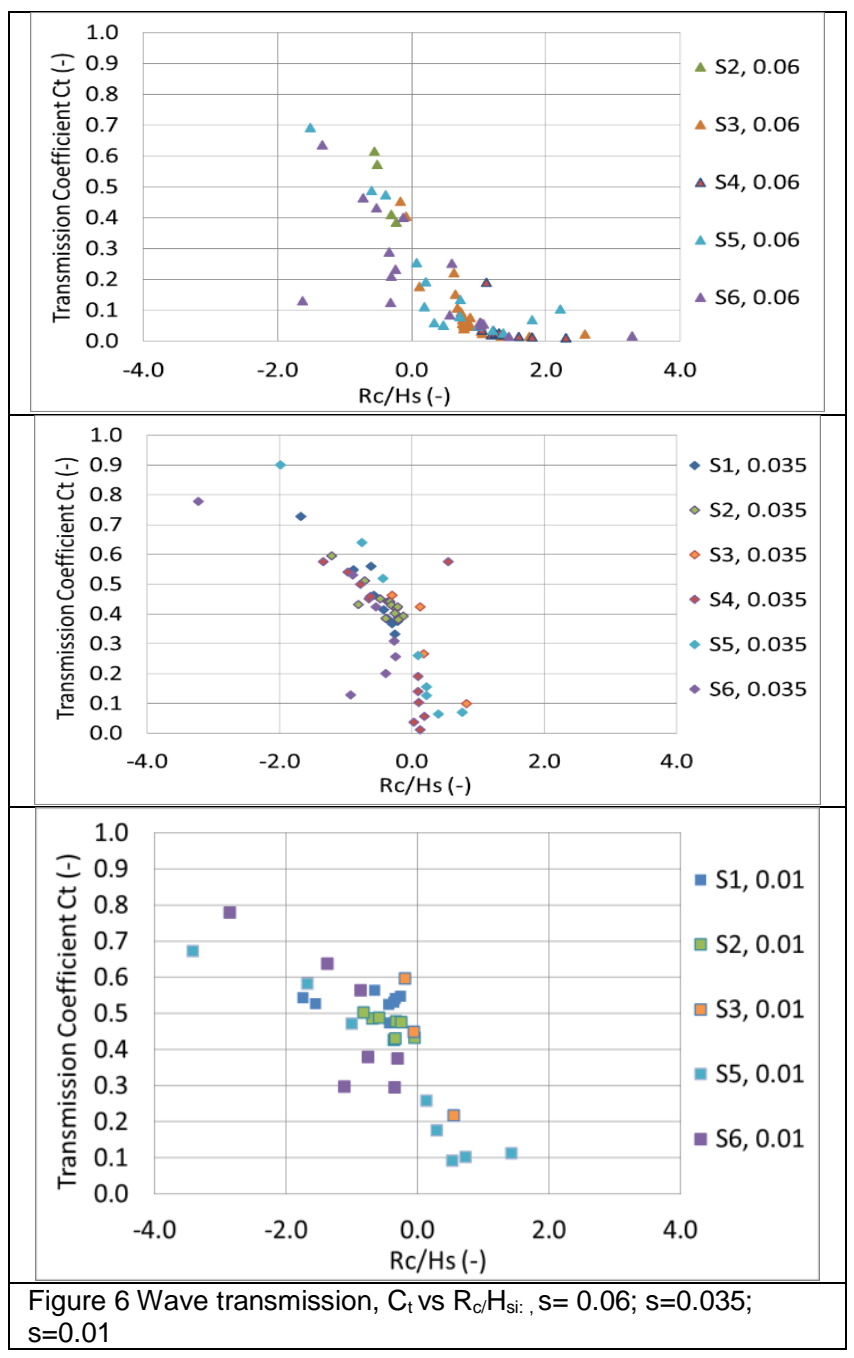

Measurements of wave transmission were then compared with the simplified prediction lines in the Rock Manual as transmission coefficients $C_{t}$ in Figure 7.

$\begin{array}{ll}-4<\mathrm{R}_{\mathrm{c}} / \mathrm{H}_{\mathrm{s}}<-1.6 & \mathrm{C}_{\mathrm{t}}=0.8 \\ -1.6<\mathrm{R}_{\mathrm{c}} / \mathrm{H}_{\mathrm{s}}<0.7 & \mathrm{C}_{\mathrm{t}}=0.32-0.3 \mathrm{R}_{\mathrm{c}} / \mathrm{H}_{\mathrm{s}} \\ 0.7<\mathrm{R}_{\mathrm{c}} / \mathrm{H}_{\mathrm{s}}<3.0 & \mathrm{C}_{\mathrm{t}}=0.1\end{array}$

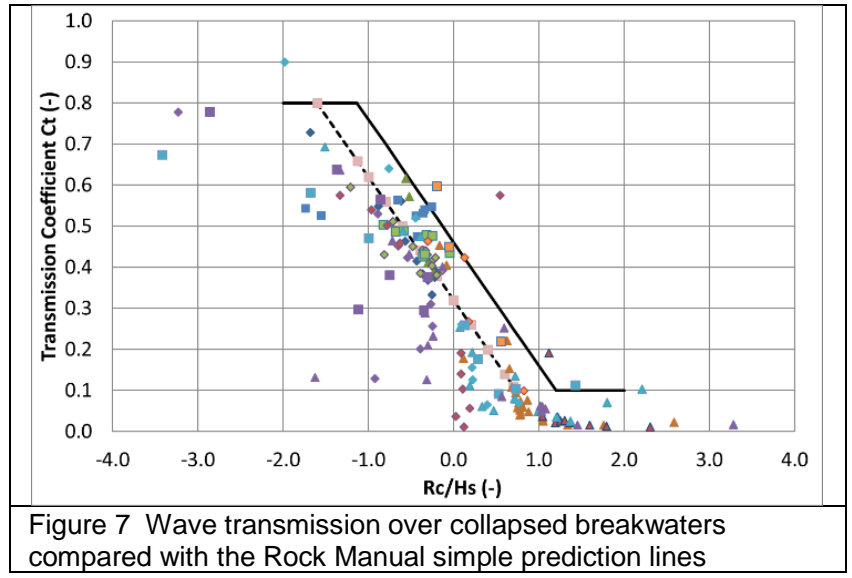

The paper will present further analysis on collapsed crest levels supported by examples from real breakwaters probably including Skateraw and Alderney.

\section{ACKNOWLEDGEMENTS}

The studies described here were supported by ICE Research \& Development Enabling Fund (ICE R\&D) as project 1315, and in part from PhD research by the first author. Additional support was given by Nick Hanousek (Industrial Trainee to HR Wallingford from Cardiff University), HR Wallingford (new wave paddle), Instrument Support (wave measurement and profiler equipment), Paul Tong (rock sorting), Clive Rayfield and team. Dr Stephen Richardson was Project Director for HR Wallingford.

Elysia Ward (student) and Dr Dave Simmonds (Plymouth University) are thanked for access to Elysia's exploratory project thesis. Support from University of Edinburgh (Professors Tom Bruce and David Ingram) for the first author's PhD studies are gratefully acknowledged.

\section{REFERENCES}

Allsop, Pearson, \& Bruce (2017) Orphan breakwaters what protection might be given when they collapse? ICE Breakwaters conference. Liverpool.

CIRIA; CUR; CETMEF (2007) The Rock Manual. The use of rock in hydraulic engineering, C683, CIRIA, London.

Hampshire, Turner, Hancock \& Guthrie (2013) In a Heugh - the strategic influence of a breakwater, Proc ICE Breakwaters Conference, ICE Publishing, ISBN 978-07277-5975-7, pp188-198. 